\title{
The study of eclampsia as a cause of severe acute maternal morbidity
}

\author{
Yoga Lakshmi S. K.*, Suvarna R.
}

Department of Obstetrics and Gynecology, KIMS Hospital and Research Centre, Bangalore, Karnataka, India

Received: 26 July 2018

Accepted: 28 August 2018

\section{*Correspondence:}

Dr. Yoga Lakshmi.S.K,

E-mail: yoga_akshu@yahoo.com

Copyright: () the author(s), publisher and licensee Medip Academy. This is an open-access article distributed under the terms of the Creative Commons Attribution Non-Commercial License, which permits unrestricted non-commercial use, distribution, and reproduction in any medium, provided the original work is properly cited.

\section{ABSTRACT}

Background: "SAMM" refers to the morbidity a woman actually suffers1. The identification of Eclampsia as a cause of severe maternal morbidity has emerged as a promising complement or alternative to the investigation of maternal deaths. The most common tool used to identify SAMM is by WHO criteria. Incorporation of near-misses into maternal death enquiries would improve the quality of care and its standardization.

Methods: A descriptive study of SAMM in the department of OBG in KIMS hospital done between Jan 2013 to June 2014. The total number of deliveries during this period were 2786. There were 43 cases of Eclampsia as a cause of SAMM. Among this, 1 case was admitted in ICU due to peripartum cardiomyopathy, MODS, HELLP syndrome. Data were collected as per Performa (facility based Maternal Near Miss Review Form [MNM-R FORM] and statistical analysis was performed.

Results: The cases of near miss have 2 or more factors responsible for it. In this study,23\% of SAMM are due to lack of resources and Lack of transport from home to health care facility. $20 \%$ due to lack of human resources. $11 \%$ due to lack of awareness. Other responsible for minor contributory factors.

Conclusions: SAMM can be decreased by identifying factors responsible for it and steps taken to resolve them. Step by step improvement to be done as all the factors are modifiable.

Keywords: Eclampsia, Maternal mortality, SAMM

\section{INTRODUCTION}

Severe acute maternal morbidity [SAMM] is "the severe life-threatening obstetric complication necessitating an urgent medical intervention in order to prevent the likely death of the mother". It is the acronym for the most popular term of "near-miss cases.

The most important causes are hemorrhage, hypertension, sepsis and dystocia. Here we will study the cases of Eclampsia as the cause of SAMM. The identification of cases of SAMM has emerged as an alternative to the investigation of maternal deaths. The cases of Eclampsia are identified by the WHO criteria. Associated factors are identified which contribute for near-miss instances in the cases of Eclampsia.
"SAMM" refers to the morbidity a woman actually suffers. ${ }^{1}$ The identification of Eclampsia as a cause of severe maternal morbidity has emerged as a promising complement or alternative to the investigation of maternal deaths.

The most common tool used to identify SAMM is by WHO criteria. Incorporation of near-misses into maternal death enquiries would improve the quality of care and its standardization. Analysis of near-miss cases will help to assess the quality of service and will suggest the areas where improvements are to be brought in both in trained personnel and in equipment and can strengthen our understanding of the disease progression that ultimately kills the women and there by empower us to prevent maternal death. 
Maternal mortality is only the tip of the iceberg; there is a large base of the severe acute maternal morbidity, the identification of which will tell the true story of the complications.

The objective of the present study was to identify associated factors responsible for Near-Miss instance in the cases of Eclampsia.

\section{METHODS}

The study was conducted in the department of Obstetrics and Gynaecology, in KIMS hospital Bangalore. This was a descriptive study for a period of 18 months from Jan 2013 to June 2014.

Cases of Eclampsia as a cause of SAMM were identified by WHO criteria. Factors associated with near miss are identified according to MNM-R form.

Data were collected on demographic characteristics including gestational age at the time of sustaining the near-miss morbidity, nature of obstetric complication, presence of organ system dysfunction/ failure, ICU admission, and the timing of Near-miss event with respect to admission.

Table 1: Method of collection of Data WHO criteria.

\begin{tabular}{|c|c|c|}
\hline Clinical criteria & Laboratory based criteria & Management based criteria \\
\hline $\begin{array}{l}\text { - } \text { Acute cyanosis } \\
\text { - } \text { Rasping } \\
\text { - } \text { Shospiratory rate }>40 \text { or }<6 / \mathrm{min} \\
\text { - } \text { Oliguria non-responsive to fluids } \\
\text { or diuretics } \\
\text { - } \text { Clotting failure } \\
\text { - } \quad \text { Loss of consciousness lasting } \\
\text { - } \geq 12 \mathrm{hrs} \\
\text { - } \text { and absence of pulse/ heart beat } \\
\text { - Stroke } \\
\text { - Jncontrollable fit/ total paralysis } \\
\text { Jaundice in the presence of pre- } \\
\text { eclampsia }\end{array}$ & $\begin{array}{ll}\text { - } & \text { Oxygen saturation }<90 \% \text { for } \\
\text { - } & \mathrm{PaO} 2 / \mathrm{min} \\
\text { - } & \text { Creatinine } \geq 300 \mu \mathrm{mol} / \mathrm{l} \text { or } 6 \mathrm{mg} / \mathrm{dl} \\
\text { - } & \mathrm{pH}<7.1 \\
\text { - } & \text { Lactate }>5 \\
\text { - } & \text { Acute thrombocytopenia } \\
\text { - } & \text { Loss of consciousness and the } \\
& \text { presence of glucose and ketoacids } \\
\text { in urine }\end{array}$ & $\begin{array}{l}\text { Use of continuous vasoactive } \\
\text { drugs } \\
\text { - } \quad \begin{array}{l}\text { Hysterectomy following infection } \\
\text { or hemorrhage }\end{array} \\
\text { - } \quad \begin{array}{l}\text { Transfusion of } \geq 5 \text { units red cell } \\
\text { transfusion }\end{array} \\
\text { - } \begin{array}{l}\text { Intubation and ventilation for } \geq 60 \\
\text { min not related to anesthesia }\end{array} \\
\text { - } \\
\text { Dialysis for acute renal failure } \\
\text { Cardiopulmonary resuscitation }\end{array}$ \\
\hline
\end{tabular}

Information on maternal deaths and deliveries conducted during the study period were obtained from the maternal mortality audit and the labour/ delivery registers.

\section{Inclusion criteria}

- All the cases of Eclampsia including Imminent eclampsia was included in this study.

- Eclampsia as a cause of SAMM identified as per WHO criteria (which includes those with organ dysfunction/ organ failure \{clinical criteria, Laboratory- based criteria, Management- based criteria\}).

\section{Exclusion criteria}

- Those who do not give consent.

- SAMM due to non-obstetric causes such as due to poisoning and trauma.

- Those >42 days of delivery or termination of pregnancy.

\section{RESULTS}

A descriptive study of SAMM in the department of OBG in KIMS hospital done between Jan 2013 to June 2014. The total number of deliveries during this period were 2786. There were 43 cases of Eclampsia as a cause of SAMM.

Table 2: Age in years.

\begin{tabular}{|lll|}
\hline Age in years & No of cases & $\%$ \\
\hline $15-19$ & 3 & 6.9 \\
\hline $20-24$ & 17 & 39.5 \\
\hline $25-29$ & 17 & 39.5 \\
\hline $30-34$ & 5 & 11.6 \\
\hline$>35$ & 1 & 2.3 \\
\hline
\end{tabular}

Among this, 1 case was admitted in ICU due to peripartum cardiomyopathy, MODS, HELLP syndrome. Data were collected as per Performa (facility based Maternal Near Miss Review Form [MNM-R FORM] and statistical analysis was performed. The maximum number 
of patients were in the reproductive age group 20-30 years. Only $2 \%$ of the patients were $>35$ years. $6.9 \%$ of the patients were in age group between $15-19$ years. $11.6 \%$ of the patients between 30-34 years (Table 2).

Majority of the patients belongs to the middle socioeconomic status, this is because of the type of patients who attend OPD in KIMS. $13.9 \%$ of the patients belongs to the lower socioeconomic groups (Table 3 ).

Table 3: Socio economic status.

\begin{tabular}{|lll|}
\hline SES & No of cases & $\%$ \\
\hline Middle & 37 & 86 \\
\hline Lower & 6 & 13.9 \\
\hline
\end{tabular}

Most of the near miss cases of about $46 \%$ were admitted with severe illness (Table 4).

Table 4: Type of admission (According to MNM-R form).

\begin{tabular}{|lll|}
\hline Type of admission of cases & SAMM & $\%$ \\
\hline $\begin{array}{l}\text { Patient admitted in hospital with } \\
\text { severe illness }\end{array}$ & 20 & 46.5 \\
\hline $\begin{array}{l}\text { Admitted with no disorder, became } \\
\text { near miss }\end{array}$ & 5 & 11.6 \\
\hline $\begin{array}{l}\text { Admitted with disorder, became near } \\
\text { miss }\end{array}$ & 16 & 37.2 \\
\hline If referred from outside & 2 & 4.6 \\
\hline Total & 43 & \\
\hline
\end{tabular}

Type of admission (According to MNM-R form).4.6\% of the patients were referred from outside. $11.6 \%$ of the patients were admitted with no disorder but became near miss. Atypical eclampsia was one such example. $37.2 \%$ of the patients were admitted with disorder and became near miss (Table 4).

Table 5: Booking status.

\begin{tabular}{|lll|}
\hline & No of cases & $\%$ \\
\hline Booked & 5 & 11.6 \\
\hline Unbooked & 38 & 88.3 \\
\hline
\end{tabular}

The majority of patients were unbooked. In Booked cases, 1 case had postpartum eclampsia. 1 case had Antepartum eclampsia inspite of antihypertensive without Imminent signs with $\mathrm{BP}=104 / 96$. Other 3 had imminent signs (Table 5).

Table 6: Gestational age.

\begin{tabular}{|lll|}
\hline GA in weeks & No of cases & $\%$ \\
\hline$<22$ & 0 & 0 \\
\hline$>22$ and $<34$ & 18 & 41.3 \\
\hline$>34$ and $<37$ & 13 & 30.2 \\
\hline$>37$ and $<42$ & 10 & 23.2 \\
\hline Post-partum & 2 & 4.6 \\
\hline
\end{tabular}

There were 2 cases of postpartum eclampsia (Table 6).

Table 7: Convulsion type.

\begin{tabular}{|lll|}
\hline Type of convulsion & No. & $\%$ \\
\hline Antepartum & 8 & 18.6 \\
\hline Post-partum & 2 & 4.6 \\
\hline Imminent & 33 & 76.7 \\
\hline
\end{tabular}

Imminent eclampsia contributes to about $76 \%$ (Table 7).

Table 8: Convulsions to admission interval in hours

\begin{tabular}{|l|l|}
\hline Time & No. of cases \\
\hline 1 to 5 & 5 \\
\hline 6 to 10 & 2 \\
\hline 11 to 15 & 2 \\
\hline $16+$ & 1 \\
\hline
\end{tabular}

One case was referred from outside with convulsion to admission interval $>16 \mathrm{hrs}$ in an unconscious with hematuria which required ICU admission, intubation, mechanical ventilation, use of cardiotonic drugs, blood transfusion (Table 8).

Table 9: Number of convulsions.

\begin{tabular}{|ll|}
\hline No. of convulsions & No. of cases \\
\hline 1 to 3 & 10 \\
\hline 4 to 6 & 0 \\
\hline 7 to 9 & 0 \\
\hline $10+$ & 0 \\
\hline
\end{tabular}

Majority delivered were preterm, 51.1\% (Table 10).

Table 10: Mode of delivery.

\begin{tabular}{|lll|}
\hline Mode of delivery & No of cases & $\%$ \\
\hline PTVD & 22 & 51.1 \\
\hline FTVD & 3 & 6.9 \\
\hline Emergency LSCS & 17 & 39.5 \\
\hline Elective LSCS & 1 & 2.3 \\
\hline
\end{tabular}

FTVD with IUD-1, FTVD with live birth-2, PTVD with live birth-18, PTVD with still birth- 4, Emergency LSCS with live birth-17, Elective LSCS with live birth-1

$39 \%$ underwent Emergency LSCS, 2.3\% underwent Elective LSCS, $6.9 \%$ had FTVD (Table 10).

Table 11: Weight of the babies.

\begin{tabular}{|lll|}
\hline Birth weight & No of cases & $\%$ \\
\hline $500-999$ & 5 & 11.6 \\
\hline $1000-1499$ & 5 & 11.6 \\
\hline $1500-1999$ & 11 & 25.5 \\
\hline $2000-2499$ & 14 & 32.5 \\
\hline $2500-2999$ & 6 & 13.9 \\
\hline$>3000$ & 2 & 4.6 \\
\hline
\end{tabular}


All the babies within $1 \mathrm{~kg}$ died (11.6\%). 1 case with atypical eclampsia, had baby weight of $>3 \mathrm{~kg}$. other case of $>3 \mathrm{~kg}$ had postpartum eclampsia with K/C/O GDM (Table 11). 32\% of the babies were in the range of 2-2.5 $\mathrm{kg}$. The cases of near miss have 2 or more factors responsible for it. In this study,23\% of SAMM are due to lack of resources and Lack of transport from home to health care facility. $20 \%$ due to lack of human resources.11\% due to lack of awareness. Other responsible for minor contributory factors. Refusal of treatment and admission, Lack of transport between health facility contributes $4.6 \%$. $11.6 \%$ due to lack of awareness. $4.6 \%$ due to lack of human resources and human expertise (Table 12).

Table 12: Associated factors responsible for near miss instances.

\begin{tabular}{|c|c|c|c|}
\hline Factors responsible & & SAMM No of cases & $\%$ \\
\hline \multirow[t]{7}{*}{ Personal/ family factors } & & 43 & \\
\hline & Delay in women seeking help & & \\
\hline & - Lack of awareness & 5 & 11.6 \\
\hline & - Lack of resources & 10 & 23.2 \\
\hline & - Past experience & 2 & 4.6 \\
\hline & Refusal of treatment & 2 & 4.6 \\
\hline & Refusal of admission & 2 & 4.6 \\
\hline \multicolumn{4}{|l|}{ Logistic problems } \\
\hline & $\begin{array}{l}\text { Lack of transport from home } \\
\text { to health care facility }\end{array}$ & 10 & 23.2 \\
\hline & $\begin{array}{l}\text { Lack of transport between } \\
\text { health facility }\end{array}$ & 2 & 4.6 \\
\hline \multicolumn{4}{|l|}{ Health personnel } \\
\hline & Lack of human resources & 9 & 20.9 \\
\hline & Lack of Human expertise & 2 & 4.6 \\
\hline & Lack of trained Obstetrician & 2 & 4.6 \\
\hline & Lack of anesthesiology & 0 & 0 \\
\hline & Attitude problem & 0 & 0 \\
\hline
\end{tabular}

\section{DISCUSSION}

In any setting, women can develop severe acute complication during pregnancy and circumstantial factors. While some of these women die, a proportion of them narrowly escape death. ${ }^{1}$ Cases of Eclampsia as a cause of SAMM were identified by WHO criteria. $^{2}$ Factors associated with near miss are identified according to MNM-R form. Although less specific, the use of disease-specific criteria has some advantages; it is easy to interpret, and the quality of care for that particular disease can be assessed. ${ }^{3}$

It is clearly illustrated in the studies that more SAMM cases are likely to die in resource-poor settings than in more developed country settings. The studies conducted in Nigeria, Benin and Malaysia give the morbidity to mortality ratio as 11-12. In present study, maternal outcome was studied with respect to mode of delivery, hospital stay, intervention required along with organ dysfunction. Siddiqui et al. The mean duration of hospital stay $6.17 \pm 0.58$ days, and maximum stay up to 50 days. ${ }^{4}$

The incidence of SAMM per 1000 deliveries in this study was 58.1. There were 162 cases of SAMM, and 6 maternal deaths during the same period. In present study, eclampsia leads the causes of SAMM followed by obstetric hemorrhage. Upadhyaya and Chaudhary, Moraes et al. and Huseyin et al. also reported the hypertensive disorders in pregnancy as leading cause of maternal illness. ${ }^{5-7}$ According to Mantel et al., study,the most common initiating obstetric conditions were hypertension in 38 women (26\%); haemorrhage in 38 $(26 \%){ }^{8}$

According to Olufemi T Oladapo et al., study $18.4 \%$ constituted near-miss events, and Shrestha et al., Abdel Aziem et al., Roopa PS et al., constitutes 13.8\%, 5.7\%, $10.6 \%$ of near-miss events respectively. ${ }^{9-12}$ Refusal of treatment may be due to poor understanding of the complication and risks and the medical interventions needed as in FIGO study. ${ }^{13}$ To conclude, any pregnant woman can develop life threatening complication with little or no advance warning. All women need to access the quality maternal health services that can diagnose and manage life threatening complications. In developing countries, woman's lower socioeconomic status, poor obstetric services, and lack of emergency transfer contributes significantly to morbidity and mortality. Obstetric ICU setup with team approach consisting of 
treatment by obstetricians, intensive care specialists, and anaesthesiologists are essential to save a maternal life. This understanding between morbidity and mortality will help in reducing substandard care and the global burden of death and long-term morbidity.

\section{CONCLUSION}

Screening for and detection of severe maternal morbidity is an important step toward promoting safe obstetric practice care. Here we have discussed only eclampsia as a cause of SAMM. Identifying the factors responsible and its management accordingly would serve as a measure of maternal health and quality of care indicator.

\section{ACKNOWLEDGMENTS}

Authors would like to thank professor Dr. Suvarna for the encouragement during the work and the department of OBG for supporting throughout work.

\section{Funding: No funding sources}

Conflict of interest: None declared

Ethical approval: The study was approved by the Institutional Ethics Committee

\section{REFERENCES}

1. Yelikar KA, Deshpande SS, Deshmukh SF. Severe Acute Maternal Morbidity in a tertiary care centre with Basic Intermediate Respiratory Care Units Setup. Int J Sci Stud 2015;3(5):36-40.

2. World Health Organization. A draft proposal for a classification system for cause-identification of maternal deaths and severe acute maternal morbidity for use a quality care tool. Unpublished document, Geneva: WHO,2008.

3. Lale Say, Robert C Pattinson, A Metin Gulmezoglu. WHO systematic review of maternal morbidity and mortality. Reproductive Health 2004,1(1):3.

4. Siddiqui SA, Soomro N, Shabih-ul-Hasnain F. Severe obstetric morbidity and its outcome in patients presenting in a tertiary care hospital of Karachi. J Pak Med Assoc. 2012;62(3):226-31.

5. Upadhyaya I, Chaudhary P. Severe acute maternal morbidity and intensive care in Paropkar maternity and women's hospital. NJOG. 2013;8(2):38-41.

6. Moraes AP, Barreto SM, Passos VM, Golino PS, Costa JA, Vasconcelos MX. Incidence and main causes of severe maternal morbidity in São Luís, Maranhão, Brazil: A longitudinal study. Sao Paulo Med J. 2011;129(3):146-52.

7. Huseyin C, Cihan K, Ramazan A, Ziya YY, Murat E, Levent Y. Near miss obstetric cases: 4 years experience of a tertiary center. Gynecol Obstet Reprod Med. 2013;19(1):19-22.

8. Mantel GD, Buchmann E, Rees H, Pattinson RC. Severe acute maternal morbidity: a pilot study of a definition for a near-miss. Br J Obstet Gynaecol. 1998;105(9):985-90.

9. Oladapo OT, Sule-Odo AO, Olatunji AO, Daniel OJ: "Near miss" obstetric events and maternal deaths in Sagamu, Nigeria: a retrospective study. Reprod Health 2005;2(1):9.

10. Shrestha NS, Saha R, Karki C. Near miss maternal morbidity and maternal mortality at Kathmandu Medical College Teaching Hospital. Kathmandu University Med J. 2010;8(2):222-6.

11. Ali AA, Khojali A, Okud A, Adam GK, Adam I. Maternal near-miss in a rural hospital in Sudan. BMC Pregnancy and childbirth 2011;11(1):48.

12. PS R, Verma S, Rai L, Kumar P, Pai MV, Shetty J.," Near Miss" Obstetric Events and Maternal deaths in a Tertiary Care Hospital: An Audit, J Preg, 2013.

13. Lawton B, MacDonald EJ, Brown SA, Wilson L, Stanley J, Tait JD et al. Preventability of severe acute maternal morbidity. Am J Obstet Gynecol 2014;210(6):557-6.

Cite this article as: Lakshmi YSK, Suvarna R. The study of eclampsia as a cause of severe acute maternal morbidity. Int J Reprod Contracept Obstet Gynecol 2018;7:4234-8. 